Revista Perspectivas Online: Exatas \& Engenharia

Agosto de 2019, v.09, n.25, p. $77-88$

ISSN: 2236-885X (Online)

DOI: $10.25242 / 885 X 92520191406$

\title{
GESTÃO AMBIENTAL E ZONEAMENTO DE ÁREAS ADJACENTES DO CAMPUS UNIVERSITÁRIO DA UFAM
}

\author{
Igor Moraes Bezerra Calixto, Carlos Henrique Mota Rodrigues, Gabriel Henrique Fonseca \\ Oliveira, Marcelo Cordeiro Ribeiro \& Rafael Alcântara Farias
}

\section{RESUMO}

CALIXTO, I.M.B.; RODRIGUES, C.H.M.; OLIVEIRA, G.H.F.; RIBEIRO, M.C.; FARIAS, R.A. Gestão Ambiental e zoneamento de áreas adjacentes do Campus Universitária da UFAM. Perspectivas Online: Exatas \& Engenharia, v. 09, n. 25, p. 77 - 88, 2019.

Este estudo avaliou o Programa de Gestão Ambiental de áreas adjacentes ao Campus Arthur Virgílio Filho da Universidade Federal do Amazonas tendo como enfoque a Avenida Grande Circular. Como se sabe, o processo de caracterização e gestão ambiental de uma região é um processo que exige a confiabilidade de dados primários e secundários, uma vez que estas informações obtidas são importantes no processo de estudo em termos qualitativos e quantitativos de uma região. Para isso, dados oficiais e legais como Instituto Brasileiro de Geografia e Estatística, o Plano Diretor do Município, legislação municipal de ocupação do território foram usados. Dentro disso, realizou-se uma análise qualitativa quanto ao processo de ocupação, presença de edificações, tipos de resíduos sólidos gerados, principais construções, fluxo de trânsito na região, presença de áreas verdes na região representada pelos limites da Avenida Grande Circular com o Campus daquela instituição de ensino superior. Assim, analisou-se como o processo de ocupação nas áreas limítrofes da Universidade Federal do Amazonas ocorreu nas seis últimas décadas, observando-se que o crescimento aconteceu de forma desordenada e sem planejamento urbano.

Palavras-chave: Programa de Gestão Ambiental; Campus Universitário; ocupação; áreas límitrofes. 


\begin{abstract}
This study evaluated the Environmental Management Program of adjacent areas to the Arthur Virgílio Filho Campus of the Federal University of Amazonas, focusing on Grande Circular Avenue. As well known, the process of environmental characterization and management of a region is a process that requires the reliability of primary and secondary data, since this information is important in the qualitative and quantitative study of a region. For this purpose, official and legal data such as the Brazilian Institute of Geography and Statistics, the Municipal Master

Plan, municipal land occupation laws were used. Within this, an qualitative analysis was made of the occupation process, presence of buildings, types of solid waste generated, main constructions, traffic flow in the region, presence of green areas in the region represented by the boundaries of Grande Circular Avenue with that higher institution Campus. Thus, it was analysed how the occupation process in the border areas of the Federal University of Amazonas occurred in the last decades, observing that the growth happened in a disorderly way and without urban planning
\end{abstract}

Keywords: Environmental Management Program; University Campus; occupation; border areas.

Universidade Federal do Amazonas - Av. General Rodrigo Octavio Jordão Ramos, 1200 , Coroado I, Manaus, AM, CEP: 69067-005, Brasil.

(*) e-mail: igormbcalixto@hotmail.com

Data de recebimento: 03/10/19. Aceito para publicação: 06/05/19.

Persp. Online: exatas \& eng., Campos dos Goytacazes, 25 (09) 77 - 88 - 2019 


\section{INTRODUÇÃO}

$\mathrm{Na}$ análise espacial de áreas circunvizinhas ao Campus Universitário Senador Arthur Virgílio Filho, a área destinada a universidade em Manaus foi criada em 1968, a partir da compra e doação de diversos terrenos e sítios localizados na Zona Leste do município, contendo áreas degradadas, pomares e áreas de florestas primárias. Até o início da década de 1980, a área da universidade apresentava uma conectividade com florestas continuas principalmente ao norte e nordeste da cidade de Manaus. Entretanto, no final desta mesma década todo o perímetro da faculdade foi ocupado por comunidades que habitam os bairros de entorno (SILVIA FORSBERG, 1999).

Atualmente a área da instituição superior é de 6,7 milhões de metros quadrados, com um perímetro de 16,9 quilômetros de terreno. Isso representa o terceiro maior fragmento verde em área urbana do mundo e o primeiro do país, o que contribuiu para a criação da Área de Proteção Ambiental - APA em 2012. A APA foi criada pelo Decreto $N^{\circ} 1503$ de 27/03/2012, tendo esta unidade de conservação (UC) 759,15 ha formado pelos fragmentos florestais do Instituto Nacional de Pesquisas da Amazônia (INPA), Universidade Federal do Amazonas (UFAM), Parque Lagoa do Japiim e área verde do Conjunto Acariquara. Neste mesmo ano, o Conselho Superior da Universidade (CONSUNI) instituiu a Política Ambiental dessa Unidade de Ensino Superior (IES).

Durante as décadas de 1980 e 1990, houve um aumento considerável do processo de ocupação desordenada, tal condição está associada a problemas de invasão nas regiões limítrofes dessa IES e do alto impacto das obras de implantação de prédios e áreas de laboratórios de campo. O crescimento populacional e as correntes migratórias advindas de estados vizinhos levaram ao aumento de habitantes na região leste de Manaus-AM. Ademais, com o advento de novas indústrias estabelecidas pelo Projeto Zona Franca de Manaus, a cidade apresentou crescimento urbano vultoso, porém sem planejamento adequado para o avanço antrópico aos diversos ecossistemas encontrados na região. Considerando as alterações sofridas pela supressão vegetal, a vulnerabilidade ambiental influenciada pelos aspectos morfogenéticos e pedogenéticos envolvidos na construção da nova paisagem e o uso científico e pedagógico que justificam existência dela, decidiu-se então executar na criação da Área de Proteção Ambiental no entorno do maior dos campi da UFAM.

A ocupação no município de Manaus ocorreu de forma desordenada e irregular. Isso ocasionou graves consequências para as florestas locais, como degradações e supressões. Esse processo, conhecido como "fragmentação florestal", traz consigo uma série de consequências ecológicas para esses ecossistemas, altera ciclos reprodutivos, características climáticas nas bordas dos fragmentos, qualidade da água nos igarapés, entre outras. Obviamente, com esse processo, muitos impactos ambientais negativos ocorreram como, por exemplo, poluição e assoreamento de igarapés, alteração climática devido ao processo crescente de desflorestamento, além da alteração do equilíbrio social e ambiental da região.

Assim, este estudo se baseia na caracterização ambiental e socioeconômica da região adjacente a UFAM representada pela Avenida Grande Circular em virtude da relevância adquirida nos últimos anos para a análise geomorfológica dos espaços urbanos vinculados aos ecossistemas que os envolvem. Com isso, o levantamento do processo ocupacional de regiões de ocupação próximas a áreas de proteção ambiental apresenta grande relevância visto que por meio destes mostrar-se-ão o cenário atual de crescimento urbano de Manaus-AM e a necessidade de reordenamento do avanço antrópico aos limites impostos pela natureza. Com isso, esta pesquisa apresenta como objetivo o levantamento qualitativo da ocupação da região limítrofe da Área de Proteção Ambiental da UFAM e a Avenida Grande Circular, localizada ao norte desta APA, para evidenciar a necessidade de novas diretrizes para o planejamento urbano do município.

Persp. Online: exatas \& eng., Campos dos Goytacazes, 25 (09) 77 - 88 - 2019

seer.perspectivasonline.com.br 


\section{METODOLOGIA}

\subsection{FISIOGRAFO DO MUNICÍPIO}

A pesquisa foi desenvolvida tendo como objeto de estudo a área de entorno do Campus da Universidade Federal do Amazonas (UFAM), localizada no município de Manaus, Amazonas, a $3^{\circ} 08^{\prime}$ de latitude sul e $60^{\circ} 01^{\prime}$ de longitude oeste do Meridiano de Greenwich, com altitude em torno de 92,9 metros acima do nível do mar e tem uma área de aproximadamente $14.337 \mathrm{Km}^{2}$ (CAVALCANTI, 2012).

Ademais, o Campus UFAM está localizado entre as coordenadas geográficas $59^{\circ} 59^{\prime} 00^{\prime \prime}$ a $59^{\circ} 57^{\prime} 07^{\prime \prime}$ oeste (W) de longitude e de latitude $03^{\circ} 06^{\prime} 30^{\prime \prime}$ a $03^{\circ} 05^{\prime} 00^{\prime \prime}$ sul (S). O campus vem sofrendo os impactos em sua estrutura ambiental, originados especialmente devido ao uso inadequado de sua área, que não considera o seu peso na qualidade de vida das comunidades circunvizinhas e sua importância como hábitat de diversas espécies locais (SILVIA FORSBERG,1999).

A área abriga grande biodiversidade de fauna e flora e tem sido alvo de pressão, cada vez mais crescente, pelas comunidades do entorno. A área verde da UFAM é considerada uma das maiores áreas verdes urbanas tropicais do mundo, a qual representa aproximadamente $25 \%$ do total das áreas verdes públicas institucionais existentes na cidade de Manaus-AM sendo um dos poucos fragmentos florestais com grande dimensão $(593,86 \mathrm{ha})$ localizado no perímetro urbano da cidade.

Acerca dessa localização espacial, a IES encontra-se na Zona Sul da Área Urbana da cidade de Manaus e possui como bairros limítrofes: Coroado (Zona Leste), São José (Zona Leste), Zumbi dos Palmares (Zona Leste), Japiim (Zona Sul), Petrópolis (Zona Sul) e Distrito Industrial (Zona Sul).

\subsection{MÉTODO}

A Resolução No 01/1986 do Conselho Nacional do Meio Ambiente (CONAMA), artigo $5^{\circ}$, inciso III, estabelece que a definição dos limites geográficos da Área de Influência (AI) de um determinado empreendimento é um dos quesitos legais para a avaliação dos impactos ambientais. Desta forma, definiu-se como Área de Influência Direta os limites do IES acrescido de 100 metros para garantir que se alcance as propriedades do entorno que utilizam ou usufruam dos benefícios da área do campus e como Área Indireta - proposição de buffer (amortecedor) de amostragem, onde existam registro de ações de interface com a área do Campus.

Para obtenção das informações necessárias para pesquisa, recursos iconográficos foram coletados com o auxílio do Google Street View, Google, 2007, mas também com o uso de um aparelho móvel digital para elaboração de memorial fotográfico da região de interesse do projeto. Ademais, as características do local foram analisadas previamente com base nas imagens do Google para posterior visita ao local realizadas em três momentos diferentes.

$\mathrm{Na}$ visita foi identificada a situação das moradias, da calçada, das paradas de ônibus, da sinalização viária, do saneamento, da rede elétrica, dos tipos de edificações, da arborização, do meio físico, entre outros. Posteriormente, a análise qualitativa dos dados foi feita com a utilização do memorial fotográfico. Ademais, outras ferramentas complementares como o Sistema de Informações Geográficas (SIGs) e o Instituto Brasileiro de Geografia e Estatística (IBGE) foram utilizadas. Destaca-se que a legislação municipal, estadual e federal no que tange aos processos relacionados à Gestão Ambiental e suas inúmeras relações também foi considerada nos estudos como o Plano Diretor do Município.

Assim realizar a avaliação e monitoramento da situação desses fragmentos, como áreas de entorno à APA UFAM, é essencial tanto para a manutenção da qualidade e equilíbrio ambiental da

Persp. Online: exatas \& eng., Campos dos Goytacazes, 25 (09) 77 - 88 - 2019

seer.perspectivasonline.com.br 
área quanto para contribuir para a melhoria da qualidade de vida da população, visto que as áreas verdes urbanas trazem uma série de benefícios.

\section{3 ÁREA DA PESQUISA}

Nesse sentido, a Universidade Federal do Amazonas foi selecionada como um dos objetos de estudo desta pesquisa em virtude das características ambientais relevantes da área (diferentes tipologias florestais, de solos, fauna), por ser um dos maiores fragmentos florestais urbanos do mundo e o segundo a nível de Brasil (CAVALCANTI, 2012) e por apresentar forte pressão antrópica, principalmente, por parte das populações que residem no entorno. Dentro disso, focou-se para a área de entorno da Avenida Grande Circular, caracterizando e setorizando esta região que foi estudada em 11 subdivisões específicas.

A Figura 1 mostra a visão aérea do Campus Universitário Senador Arthur Virgílio Filho, destacando-se a área de enfoque do estudo implementado de Gestão Ambiental e Zoneamento da região da Avenida Grande Circular em Manaus-AM.

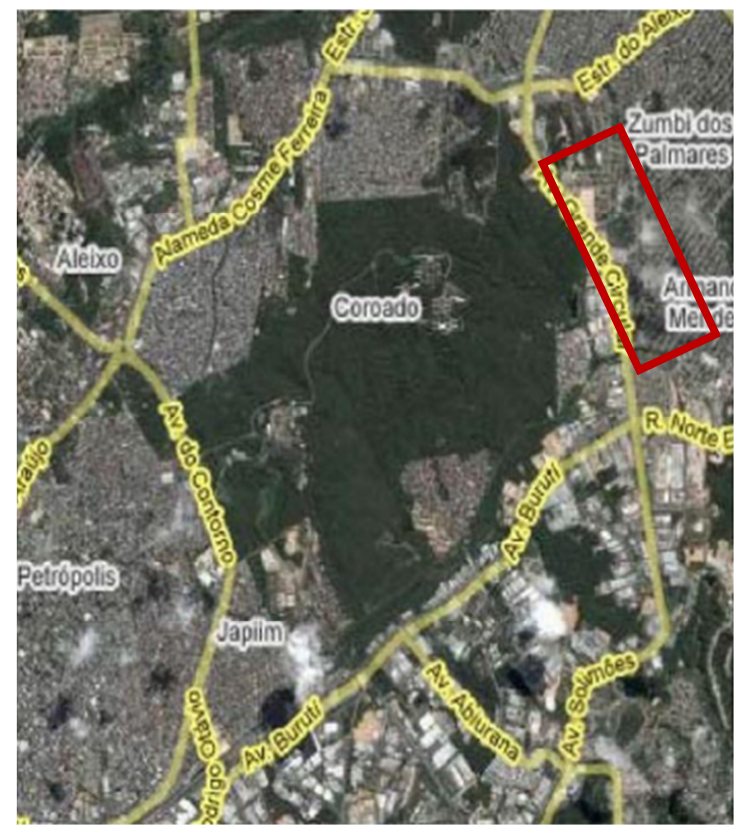

Figura 1: Projeção Aérea do Campus Universitário Arthur Virgílio Filho. Manaus-AM. Fonte: Adaptado de CAVALCANTE, 2012.

\subsection{COLETA DE DADOS}

\subsubsection{Primários}

A coleta de dados foi realizada através do levantamento de materiais cartográficos para a área estudada. $\mathrm{O}$ material utilizado foi proveniente de dados obtidos da Secretaria Municipal de Meio Ambiente e Sustentabilidade (SEMMAS). A organização do banco de dados teve como objetivo facilitar o acesso as informações e possibilitar o acesso as mesmas. Foram incorporados dados vetoriais do limite da área do campus, rede hidrográfica, solos, vegetação, curvas de nível, área construída, estradas e trilhas.

Persp. Online: exatas \& eng., Campos dos Goytacazes, 25 (09) 77 - 88 - 2019

seer.perspectivasonline.com.br 
Adicionalmente, fez-se uma pesquisa de campo a respeito da área de entorno do Campus Universitário Senador Arthur Virgílio Filho, com enfoque em termos de ocupação, geração de resíduos sólidos, presença de edificações e avaliação dos tipos de construção. Para isso, fez-se uma revisão da literatura com os principais artigos dos últimos 10 anos tratando sobre processos de setorização, zoneamento, legislação ambiental e gestão ambiental de espaços urbanos. Posteriormente foi feita uma análise de dados primários através de captação fotográfica da região de estudo.

\subsubsection{Secundários}

Para tratamento de dados qualitativos de forma secundária, uma atividade em campo foi desenvolvida com o objetivo de registrar as áreas de ocorrência de mudanças, degradação e os principais fatores de ação antrópica na área verde do Campus, como áreas de depósito de lixo, desmatamento, invasões e outros. Tanto a área do entorno como áreas no interior do Campus foram percorridos e nos pontos identificados como áreas de degradação, foram fotografados e adquiridos pontos com um Global Positioning System (GPS). Outros autores já referendaram tais pesquisas para estudos de áreas adjacentes à UFAM como CAVALCANTE (2012) que caracterizou o processo ocupacional das regiões circunvizinhas à universidade.

\subsection{ANÁLISE QUALITATIVA}

A partir das informações obtidas pela metologia aplicada nesta pesquisa, obtiveram-se informações relevantes quanto ao processo de ocupação e desenvolvimento social, econômico e ambiental da região circunvizinha à UFAM. Por meio destas, analisaram-se os aspectos qualitativos da urbanização com os limites da natureza e o bem-estar da sociedade no entorno da área de estudo.

\section{RESULTADOS E DISCUSSÃO}

Realizou-se o levantamento de todas as edificações no local observado, Avenida Grande Circular como detalhado na Figura 2 com extensão aproximada de $2,5 \mathrm{~km}$. Observou-se que na parte que faz fronteira com a Universidade Federal do Amazonas não há presença de edificações residenciais. Ademais, existe na fronteira a presença de uma maternidade, uma área de propriedade privada, empresas de distribuição e logística além de uma área poluída com lixo industrial descartado irregularmente. No lado esquerdo da Avenida Grande Circular, ou seja, o lado que não faz fronteira com a UFAM, observou-se a presença de uma garagem de ônibus de empresa municipal, empresas de logística, um supermercado, uma área em construção, algumas residências, uma vendedora de sucatas, borracharias e serviços automotivos, duas áreas não construídas, além de uma lanchonete e um restaurante.

Além disso, a partir da área de estudo, as vias e os passeios foram identificados e caracterizados, descrevendo as inadequações (obstáculos, variação de níveis, etc.) a partir do que recomenda a legislação. Verificou-se também as formas de acesso aos passeios (pessoas e veículos), a presença ou não de elementos de acessibilidade para portadores de deficiência ou de necessidades especiais, a presença ou não de sinalização. Quanto às unidades arquitetônicas identificadas os dados indicaram que há edificações de madeira e alvenaria, com uso residencial, comercial, misto, institucional, a ocupação do lote com ou sem recuo, presença ou não de elementos de acessibilidade para portadores de deficiência e o entorno.

Persp. Online: exatas \& eng., Campos dos Goytacazes, 25 (09) 77 - 88 - 2019

seer.perspectivasonline.com.br 




Figura 2: Objeto de Estudo do processo ocupacional. Manaus-AM.

Adicionalmente, existem áreas em construção na região limítrofe. As principais vias de acesso se dão pela Avenida Cosme Ferreira (Figura 3) do sentido sul para norte, sendo a região em estudo importante subárea para a Zona Leste da Cidade. Foram encontrados também empreendimentos de caráter comunitário ou social como uma Maternidade.

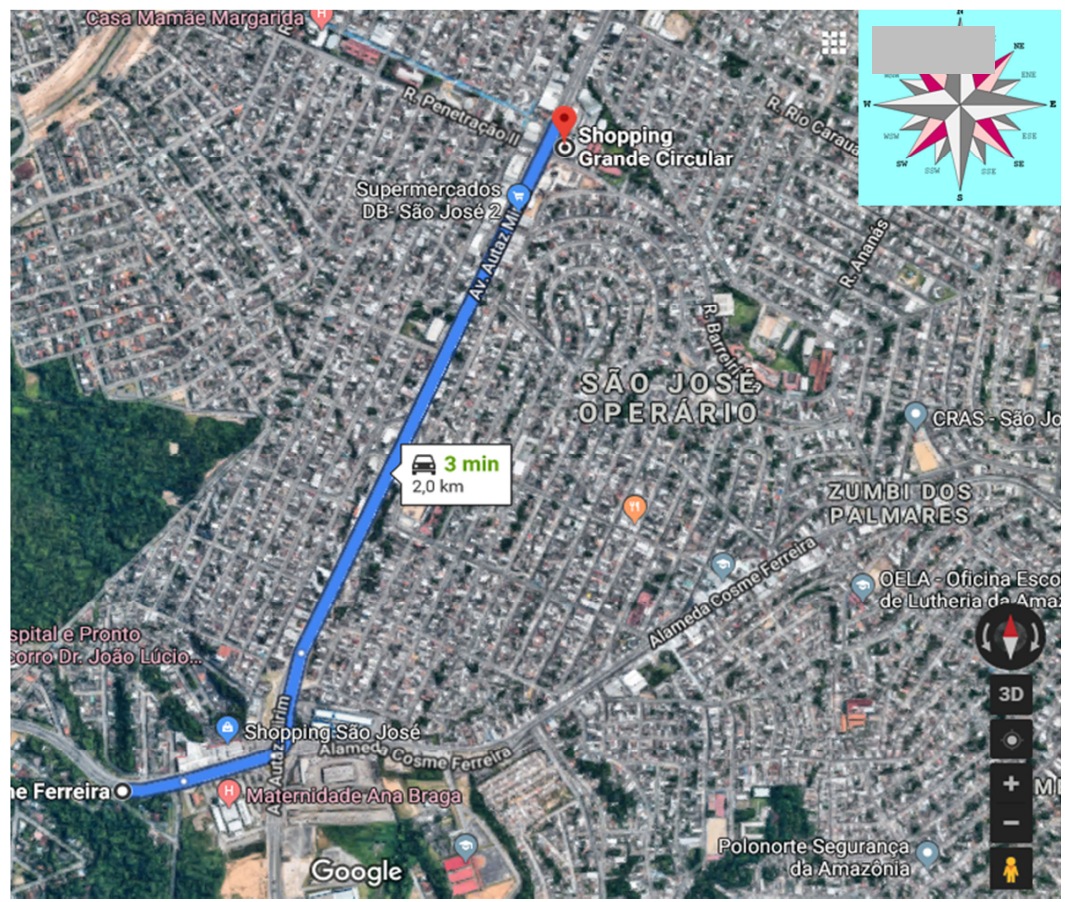

Figura 3: Principal via de acesso para Avenida Grande Circular. Manaus/AM.

Persp. Online: exatas \& eng., Campos dos Goytacazes, 25 (09) 77 - 88 - 2019 seer.perspectivasonline.com.br 
Outra característica relevante encontrada na visita de campo foi a ausência de políticas públicas de tratamento dos resíduos sólidos na região, uma vez que não foi encontrada na região analisada um programa de tratamento e coleta dos resíduos sólidos gerados pela área. Pelo contrário, verificou-se que existiam inúmeros depósitos de lixeiras clandestinas, violando códigos ambientais e o Plano Nacional de Resíduos Sólidos.

Quanto ao projeto de arborização da avenida principal, atestou-se quase ausência de árvores no canteiro central, revelando um problema habitual de Manaus, que é a problemática de questão de arborização da cidade. Além disso, como se trata de uma área vizinha ao Campus Universitário Senador Arthur Virgílio Filho, foi encontrada parte da Área de Proteção Ambiental do Campus Ufam, Acariquara e Eliza Miranda, que obviamente mostra a importância adquirida por esta unidade de conservação para a manutenção da vida vegetal em uma região com intenso avanço urbano, de forma majoritariamente desordenada.

Além disso, existem diferentes empreendimentos comerciais, sendo importante caracterizá-los em termos ocupacionais, de construção e influência socioeconômica na região de estudo como destacado na Figura 4. Verifica-se a existência de dois edifícios comerciais de ocupaçáo expressiva de área (Riachuelo e Atacadão). Além disso, existem instalações industriais (Rapidão Cometa, Procargo e Rio Limpo) que desempenham importante influência socioeconômica da região estudada. Ademais, existe um empreendimento de caráter social de atendimento público. Ressalta-se ainda que devido às limitações impostas pelo Plano Diretor do Município, a maioria das edificações localizam-se na parte superior do iconograma uma vez que a parte inferior é considerada uma área de proteçáo ambiental e assim de preservação permanente.

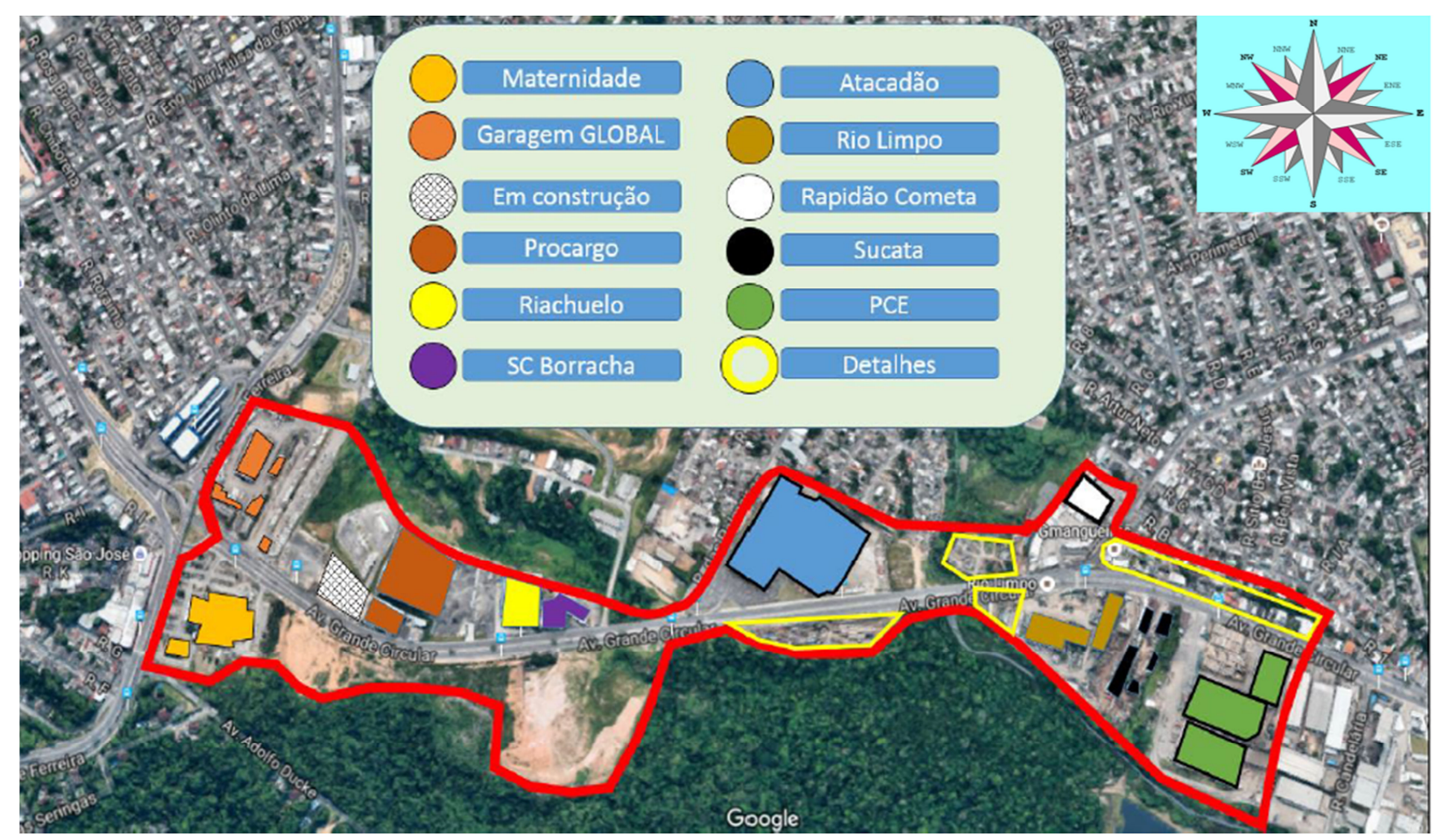

Figura 4: Setorização da região por empreendimentos e atividades. Manaus-AM.

Outra classificação necessária aos objetos de estudo são referentes às obras de caráter comercial na região. Com isso, a Figura 5 mostra a setorização específica de organizações econômicas encontradas na Avenida Grande Circular.

Persp. Online: exatas \& eng., Campos dos Goytacazes, 25 (09) 77 - 88 - 2019

seer.perspectivasonline.com.br 


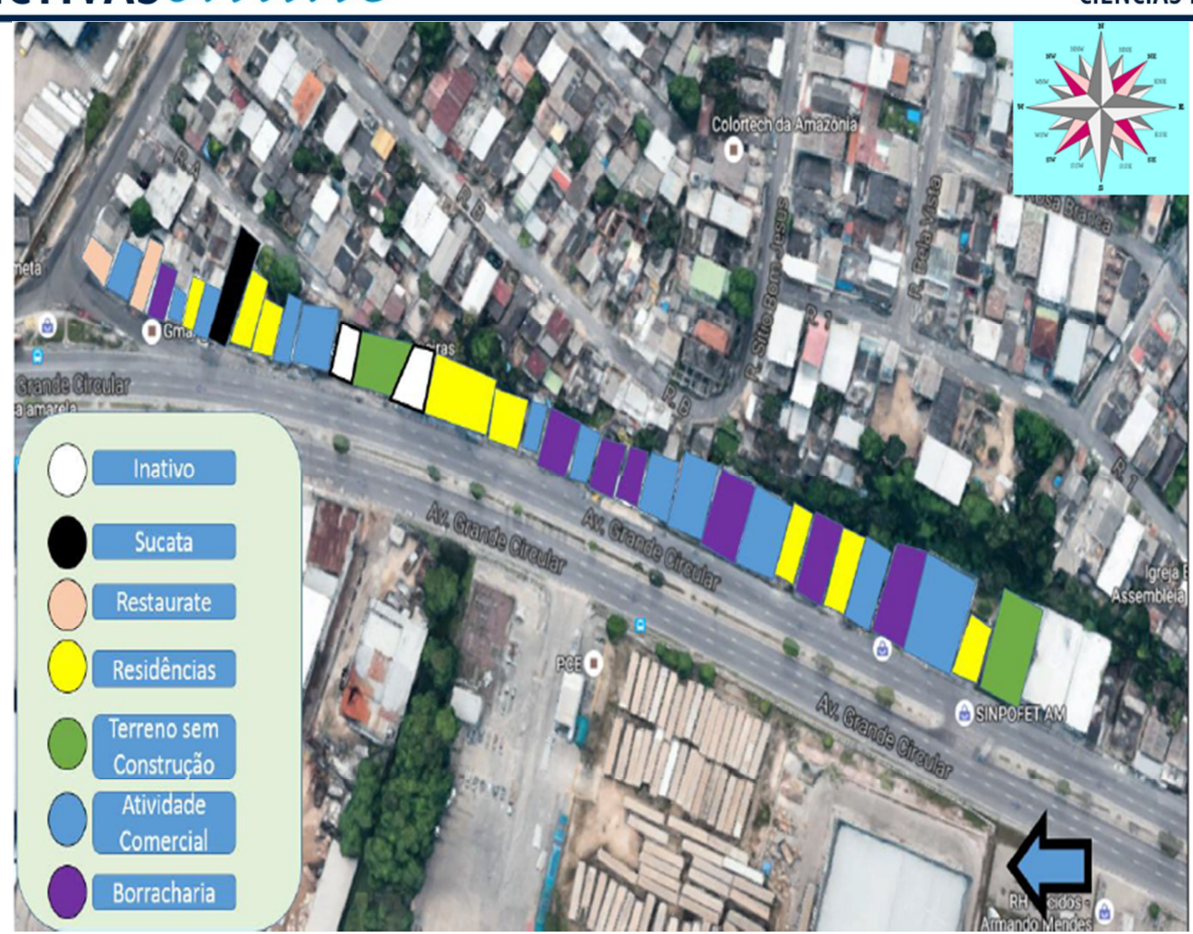

Figura 5: Setorização dos empreendimentos comerciais da região objeto de estudo. Manaus-AM.

Destaca-se que existe uma enorme variedade de atividades comerciais na região, com maior desenvolvimento de para atividades de pequeno e médio porte, como borracharias, restaurantes, mercadinhos, entre outros. No entanto, nesta mesma área, verifica-se a presença de empreendimentos comerciais de grande porte como um Atacadão.

Ademais, existem importantes construções de caráter social na região sendo importante caracterizá-los. Como exemplo, destaca-se uma maternidade que ocupa uma grande área e exerce importante influência de atendimento para os moradores da região. A Figura 6 mostra a zona de influência do hospital na região de estudo.

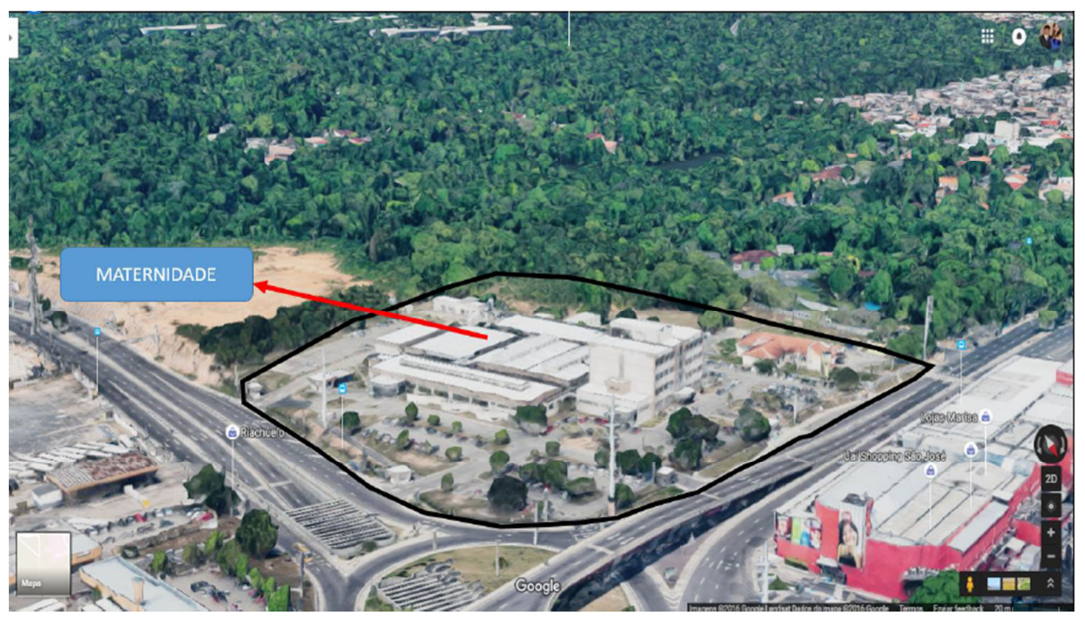

Figura 6: Empreendimento de caráter social da região de estudo. Manaus-AM.

A Figura 7 mostra que a arborização no canteiro central entre as divisórias nos dois sentidos da Avenida é nula pelo perímetro da Avenida Grande Circular, o que revela um grande problema da cidade que é a integração do meio urbano com os projetos importantes de arborização para a manutenção de uma cidade equilibrada entre os avanços antrópicos e a natureza.

Persp. Online: exatas \& eng., Campos dos Goytacazes, 25 (09) 77 - 88 - 2019

seer.perspectivasonline.com.br 


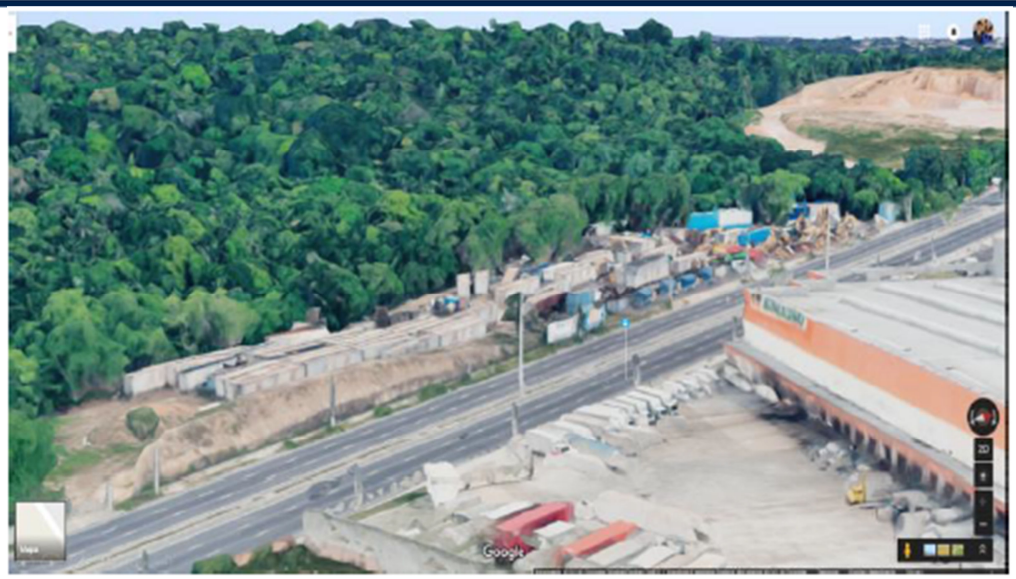

Figura 7: Caracterização da via de acesso da Avenida Grande Circular. Manaus-AM.

No entanto, observa-se uma contradição na Avenida. Apesar da arborização irregular, encontra-se uma enorme área verde de preservação permanente com presença diversificada de espécies vegetais, o que revela os contrastes da Cidade de Manaus. Isso mostra que ainda existe muito espaço para avançar nestas questões. Em termos de sinalização horizontal e vertical, verificou-se que existe uma irregularidade dessas sinalizações, uma vez que boa parte do perímetro da Avenida não contem estas sinalizações de maneira adequada.

Adicionalmente, como boa parte da zona leste da cidade de Manaus, a região em estudo se apresenta de maneira irregular e heterogênea, com diversos tipos de edificações residenciais, sendo possível caracterizar que boa parte dessas residências são de moradores permanentes, sendo uma região que possui problemas de saneamento básico. Além disso, existem problemas estruturais de algumas residências, uma vez que foram instaladas em áreas de barrancos que são propícias a desastres naturais. Percebeu-se também que a maioria das edificações não possuem arborização, gerando problemas secundários, como ilhas de calor, falta de qualidade do ar e aumento médio térmico. A Figura 8 descreve este perfil encontrado para as habitações da região.
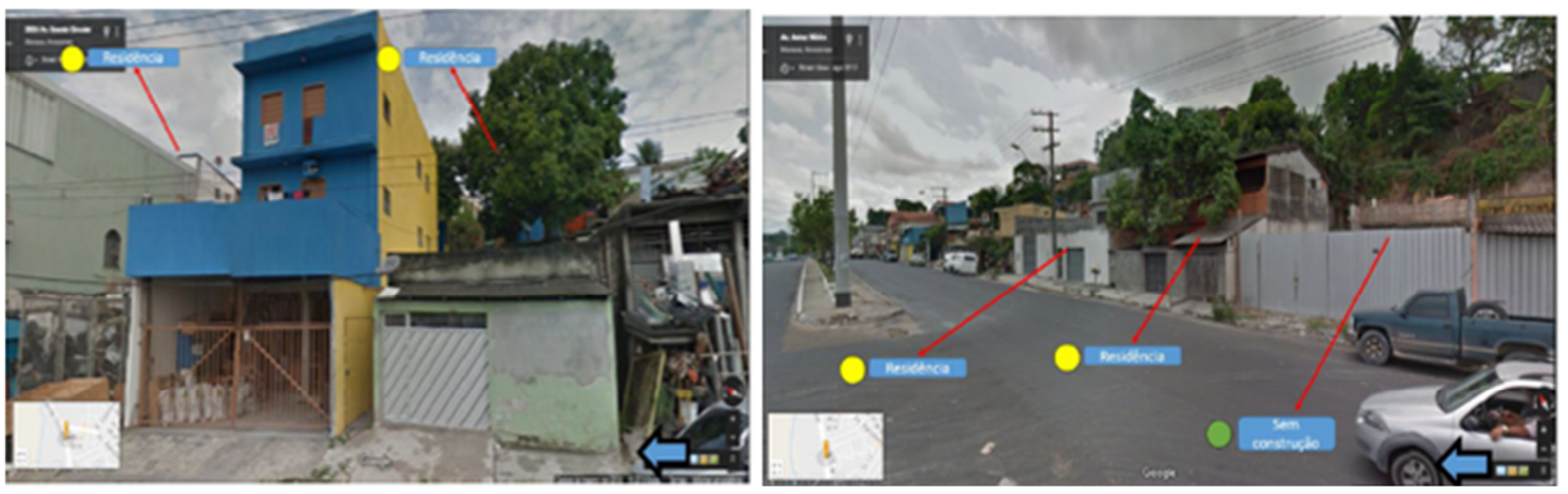

Figura 8: Setorização dos empreendimentos residenciais da região de estudo. Manaus-AM.

Outro aspecto avaliado neste estudo foi o levantamento da existência de inúmeros depósitos irregulares de resíduos sólidos, infringindo a Política Nacional dos Resíduos Sólidos e representando potencial impacto ambiental na região que abriga estes depósitos a céu aberto. Entre os potenciais impactos ambientais, estão a contaminação de lençóis freáticos, a alteração da vida da fauna e flora, o lançamento de gases poluentes e desmatamento. A Figura 9 mostra a presença de depósitos ilegais de

Persp. Online: exatas \& eng., Campos dos Goytacazes, 25 (09) 77 - 88 - 2019

seer.perspectivasonline.com.br 
sucatas e resíduos sólidos em áreas limítrofes à Área de Preservação Permanente do Campus Universitário da Universidade Federal do Amazonas.

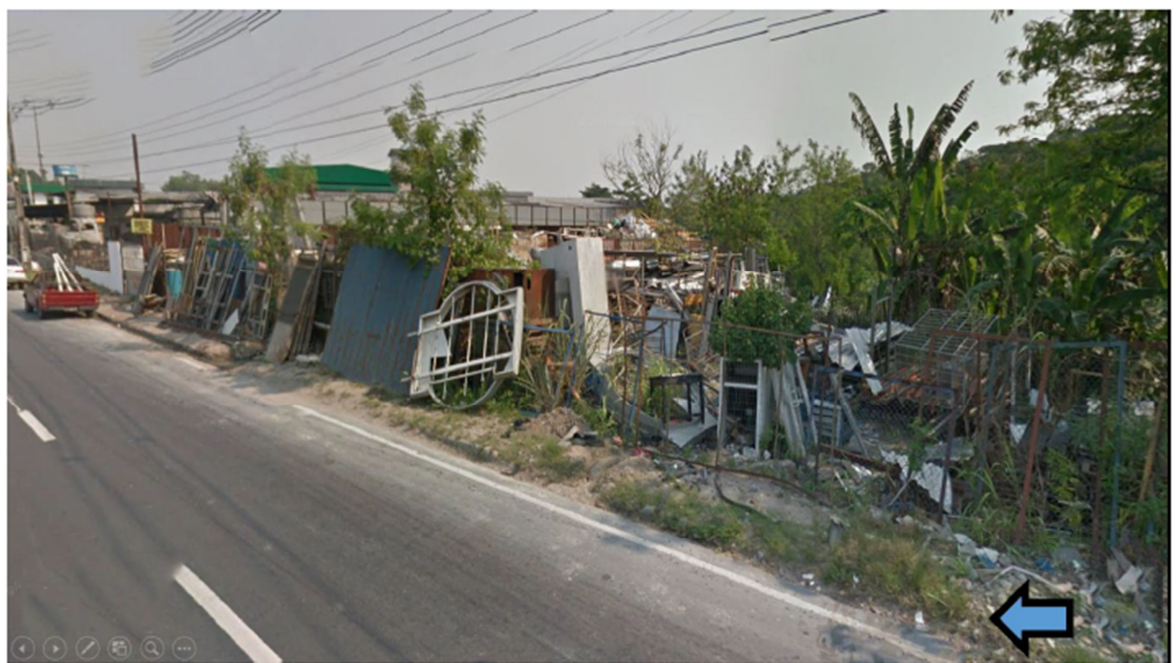

Figura 9: Identificação de lixeiras e depósitos clandestinos de resíduos sólidos. Manaus-AM.

Com isso, observou-se que o processo ocupacional nas áreas vizinhas do Campus Universitário da UFAM ocorreu de forma desordenada com impactos ambientais, sociais e econômicos à população que habita esta região.

\section{CONCLUSÕES}

O diagnóstico do Zoneamento Ambiental do Campus possibilitou a análise do processo ocupacional da área limítrofe, sendo possível observar a existência de lixeiras clandestinas, ausência de sinalização horizontal e vertical, construção de edificações em espaços irregulares, poluição sonora e visual, entre outras problemáticas. Observou-se que existem evidentes problemas ambientais na região estudada em virtude da ausência de políticas fiscalizatórias de investigação de ocupação e desenvolvimento de áreas fronteiriças às regiões de preservação ambiental permanente.

Ressalta-se que a gestão da universidade não funciona como um mecanismo protetor para as ações institucionais e não tem a intenção de limitar o uso da floresta do Campus, mas de estabelecer procedimentos que possam exponenciar as formas de uso, garantindo medidas capazes de prevenir, eliminar ou atenuar efeitos negativos ao meio ambiente e a qualidade de vida das comunidades que nesse Campus trabalham ou que dele são vizinhos. Além disso, visa estimular a participação e cooperação de diversos agentes sociais, institucionais, empenhados e comprometidos com a questão ambiental.

Ademais, o monitoramento da área verde do IES e o planejamento de uso da mesma é essencial para a conservação dessa área que contribui em muitos aspectos para uma melhor qualidade de vida da população de Manaus. Destaca-se que a área da UFAM abriga espécies endêmicas como o Sauim-de-coleira (Saguinnus bicolor) e diversas espécies de animais como cutias e pacas, sendo fundamental a implementação de programas de gestão ambiental de proteção e reordenamento da ocupação dos bairros vizinhos ao campus universitário.

Persp. Online: exatas \& eng., Campos dos Goytacazes, 25 (09) 77 - 88 - 2019

seer.perspectivasonline.com.br 


\section{REFERÊNCIAS BIBLIOGRÁFICAS}

ARAÚJO, L.M. de. Produção do espaço intra-urbano e ocupações irregulares no conjunto habitacional de Mangabeira, João Pessoa - PB. Pesquisa em andamento junto ao programa de Pós Graduação em Geografia da UFPB, 2005.

CAVALCANTI, D.C. Geoprocessamento aplicado à proteção ambiental do Campus Ufam. Dissertação de Mestrado, Manaus, 2012.

FUNDAÇÃO UNIVERSIDADE DO AMAZONAS. Plano Diretor da Universidade do Amazonas. 1978-1982. Manaus, 1977.

IBGE - Instituto Brasileiro de Geografia e Estatística. Noções Básicas de cartografia. Rio de Janeiro, IBGE, 1999.

SILVIA FOSBERG, M.C. Protecting na urban forest reserve in the Amazon: a multi-scale analysis of edge effects population pressure and institutions. Tese de Doutorado, Indiana University, 1999. 